\title{
PARATEXTOS EDITORIAIS NA ERA DA CONVERGÊNCIA DE MÍDIAS
}

Marina Burdman da Fontoura é mestranda em Literatura, Cultura e Contemporaneidade na PUC-Rio. E-mail: marinabdf@hotmail.com

\section{Resumo}

Pretende-se repensar, à luz das mudanças no meio literário incentivadas pelo advento das tecnologias digitais, a relação entre obra e paratextos, estes últimos definidos por Gérard Genette como aparatos que giram em torno do texto principal de um livro. Na literatura contemporânea, com o maior trânsito do leitor entre plataformas, os paratextos exercem outras funções e ganham cada vez mais importância em comparação à obra considerada principal.

\begin{abstract}
This article intends to analyze the relationship between the book and its paratexts, defined by Gérard Genette as narratives which surround the main text of a book, considering the changes in the literary field increased by the digital technologies. In contemporary literature, with the migration of the readers and the texts to other platforms, the paratexts develop other functions and are becoming increasingly important if compared to the main narrative.
\end{abstract}

A participação de escritores em redes sociais, sites, blogs e programas de televisão é característica cada vez mais comum na literatura brasileira. Seja em paratextos ou em obras transmídia, a figura do autor ganha centralidade e adquire também novas funções no campo editorial. A mediação entre obra e leitor cabe, hoje, menos a avaliações de críticos ou a matérias na imprensa e passa a ser papel do próprio escritor, que, por meio de diferentes dispositivos, alcança a atenção do público. O texto literário não apenas migra do livro para outras plataformas, mas também é produzido exclusivamente para esses meios e chega ao leitor sob diferentes formas. Blogs institucionais, trailers de livros e perfis em redes sociais são alguns dos produtos midiáticos em que o escritor se apresenta na literatura contemporânea.

Gérard Genette, no livro Paratextos editoriais, classificou os paratextos como textos que acompanham o texto principal de um livro, influenciando, assim, o modo de leitura da obra. Título, prefácio, posfácio, notas e entrevistas com o autor são exemplos de paratextos, que podem ser encontrados dentro ou fora do livro. Ainda segundo Genette, os paratextos contribuiriam para o modo de leitura do texto considerado principal e ajudariam o leitor a atribuir sentido ao livro de acordo com a vontade dos responsáveis pela sua publicação. O teórico francês defende que existem diversos tipos de paratexto e que cada trabalho se classifica e se organiza de maneira diferente, não apontando para uma regra ou para uma única forma de análise desse tipo de texto. Ele observa, inclusive, que as mudanças tecnológicas podem fazer surgir outros tipos de paratexto, seja no próprio livro impresso ou em outros dispositivos midiáticos.

Tal observação de Genette contribui para a reflexão sobre algumas mudanças no mercado editorial e no modo de consumo e de produção no campo. O texto literário, hoje, pode ser encontrado em diferentes plataformas, tornando-se acessível no computador, em tablets e até celulares. Além disso, é possível perceber que também os paratextos se encontram cada vez mais presentes em diferentes meios. Eles acompanham a migração do texto considerado principal para as plataformas digitais e, além disso, também se multiplicam e assumem novos formatos, chegando ao leitor de outras maneiras. Isso é, os paratextos não deixam de exercer, nas novas plataformas de leitura, suas antigas funções, manifestando-se na forma de, por exemplo, prefácio e 
notas, mas o que se modifica de forma mais intensa com essas migrações e alterações no campo literário são os paratextos que se encontram fora do suporte em que circula o texto principal. Se antes eles eram restritos a entrevistas com escritores, críticas de rodapé dos jornais e algumas ações das editoras, hoje ganham novos formatos e configurações, contribuindo, entre outras coisas, para as mudanças de função pelas quais o autor passa na literatura contemporânea.

Para compreender melhor a situação dos paratextos hoje, faz-se necessário pensar sobre as mudanças em curso referentes à própria concepção de literatura, principalmente devido ao processo de transição entre a cultura impressa e a cultura digital. Segundo Vilém Flusser, o ato de escrever em linhas sobre uma superfície de papel, característica da cultura impressa, teria marcado a passagem de um mundo pautado por representações de imagens, associado ao mágico e ao ritual, para uma organização social em que um pensamento racional e ordenado predomina (FLUSSER, 2010, p. 31). A perpetuação da escrita em relação a uma sociedade oral teria feito com que uma concepção de mundo baseada em imagens tivesse dado lugar a um pensamento histórico conformado em linhas. De acordo com o filósofo, teria havido uma "tradução do código bidimensional das imagens para o código unidimensional das linhas" (FLUSSER, 2010, p. 31).

Durante esse processo, teria ocorrido uma codificação de imagens em conceitos, o que teria incentivado uma compreensão mais progressiva da história, característica da cultura ocidental moderna, fundamentada na documentação e na memória. A cultura da escrita, segundo Flusser, seria também a cultura do pensamento discursivo e histórico, e essa característica estaria refletida no próprio ato da escrita, que envolve pausas contemplativas que nos direcionariam para um pensamento crítico e também para a consciência histórica. $\mathrm{O}$ ato de escrever exige interrupções para estimular a reflexão, e a cultura ocidental seria amparada por essa lógica, tendo sua história contada de forma linear, assim como a estrutura de sua escrita.

Para ele, estaríamos vivendo um estágio de transição entre um pensamento literal e um outro, característico da cultura digital, que se ampararia em um código numérico binário. Enquanto o primeiro teria como marca a audição, o segundo estimularia o campo visual, o que tornaria possível o que o filósofo chama de agir criativamente. Desse modo, não dependeríamos mais de um pensamento linear e lógico e poderíamos, portanto, pensar e agir de forma inventiva:

Agora, uma vez que os numerais começam a se livrar da pressão das letras e o contar torna-se algo mecânico, a força da imaginação pode se desdobrar. Os numerais, que passaram, ao longo dos séculos, por um banho de depuração da disciplina da clareza e da distinção, podem agora ser colocados a serviço de uma força da imaginação criadora, como nunca antes em qualquer lugar eles puderam se realizar. (FLUSSER, 2010, p. 51)

Apesar de não ser possível prever de forma exata o curso das mudanças na linguagem e nos costumes dos autores e leitores, percebe-se que a cultura digital já se mostra, em muitos aspectos, diferente da cultura impressa. Textos e paratextos apresentam-se na forma de imagens e áudios, estabelecem ligações entre si por meio de 
links e hiperlinks, e, assim, veem-se imersos em um processo de remissão infinito entre eles e os vários conteúdos produzidos na rede. Neste contexto, torna-se difícil distinguir onde começa ou termina uma obra literária, ou até mesmo o que poderia configurar uma. Diferentemente dos textos publicados em livros impressos, organizados e editados para serem lidos da maneira como obras acabadas, o texto online muitas vezes continua recebendo informações mesmo depois de publicado e estabelece conexões com outros textos, de diversas naturezas, que circulam no ambiente digital. Além disso, ele muitas vezes fica disponível para intervenções dos leitores, o que acaba por constituir uma rede interminável de escrituras e reescrituras.

Mesmo que não se possa afirmar que as técnicas sejam as únicas causas de transformações na cultura, é evidente que elas impulsionam mudanças no modo como a sociedade se organiza e, principalmente, se comunica. De acordo com Flusser, "uma consciência em processo de transformação clama por técnicas inovadoras, e uma técnica inovadora transforma a consciência" (FLUSSER, 2010, p. 35). Vê-se, assim, que a invenção de uma técnica comunicacional pode influenciar diversas mudanças no modo de contar e vivenciar a história, além de interferir na produção artística e cultural, como também foi o caso da invenção do códex, no século IV, e da prensa, no século XV, que ajudaram, de formas distintas, a perpetuar a cultura impressa tal como a entendemos hoje.

Em Os desafios da escrita, Roger Chartier ressalta que há uma pluralidade de usos possíveis para uma determinada técnica e que o modo como ela é utilizada não pode ser atribuído a uma suposta característica intrínseca a ela. O historiador assinala ainda que a mudança de hábito gerada pelo advento de novas tecnologias não vem imediatamente após sua invenção. Ao pensar sobre as possíveis mudanças que podem ocorrer baseadas na perpetuação do livro eletrônico, ele afirma que "a longa história da leitura mostra com firmeza que as mutações na ordem das práticas são geralmente mais lentas do que as revoluções das técnicas e sempre em defasagem em relação a elas" (CHARTIER, 2002, p. 112).

As mudanças na cultura incentivadas pelas tecnologias, portanto, acontecem de forma gradual e não fazem surgir imediatamente um novo cenário social. Isso fica evidente quando se reflete sobre a contemporaneidade e sobre as transformações sociais e culturais que acompanham o desenvolvimento de tecnologias digitais, sendo o computador o principal exemplo. Hoje, tem-se um significativo avanço na tecnologia mas ainda não há definições ou respostas sobre qual seria seu papel na arte, na economia ou na política, por exemplo. A lentidão das transformações citada por Chartier é perceptível, ainda, quando se reflete sobre a produção artística de hoje e não se percebe de forma clara um padrão estético dos trabalhos realizados com o auxílio das tecnologias digitais. Na literatura, por exemplo, o meio digital é ainda pouco explorado se for levada em conta suas potencialidades. Tem-se a tecnologia, porém as mudanças ainda não são claras.

Já é evidente, no entanto, que essas tecnologias não afetam isoladamente setores como a arte, a política ou a economia. O processo de transição entre uma cultura e outra é acompanhado por transformações estruturais mais profundas, sendo as tecnologias 
coautoras de mudanças sociais amplas capazes de reconfigurar até mesmo o modo de percepção do tempo e da história, como mostrou Flusser. Segundo Henry Jenkins, vivemos na cultura da convergência, que tem como tendência a interação de velhas e novas mídias, o fluxo de conteúdos entre plataformas e o comportamento migratório dos públicos dos meios de comunicação. Para ele, "convergência é uma palavra que consegue definir transformações tecnológicas, mercadológicas, culturais e sociais" (JENKINS, 2009, p. 29). É, portanto, apenas ao entender a convergência de mídias como uma característica contemporânea, que se podem pensar também essas mudanças de paradigma no campo artístico.

Pierre Lévy, em Cibercultura, questiona a expressão "impacto" quando se trata da relação entre cultura, sociedade e tecnologia. Para ele, o uso da "metáfora bélica" não é adequado pois coloca as tecnologias como fatores externos à cultura e não as vê como parte dela. Segundo Lévy, é "impossível separar o humano de seu ambiente material, assim como dos signos e das imagens por meio dos quais ele atribui sentido à vida e ao mundo" (LÉVY, 2010, p. 22). Assim, seria preciso entender as tecnologias como produtos da sociedade e da cultura, não sendo adequado trabalhar essas três entidades separadamente, já que a distinção entre elas seria meramente conceitual.

Para tentar explicar o uso da expressão "impacto", Lévy recorre à velocidade com que as transformações começam a acontecer na vida das pessoas após o advento de novas técnicas, o que muitas vezes acaba por gerar um espanto e dá às tecnologias um aspecto de "outro" ameaçador. Ele defende ainda que, apesar de essas mudanças serem mais perceptíveis para nós, o processo de transformação é mais complexo do que essa sensação de aceleração e velocidade resultante do contato de uma sociedade com um tecnologia recém inventada. Segundo Lévy,

Aquilo que identificamos, de forma grosseira, como "novas tecnologias" recobre na verdade a atividade multiforme de grupos humanos, um devir coletivo complexo que se cristaliza sobretudo em volta de objetos materiais, de programas de computador e de dispositivos de comunicação. É o processo social em toda sua opacidade, é a atividade dos outros, que retorna para o indivíduo sob a máscara estrangeira, inumana, da técnica. (LÉVY, 2010, p. 28)

Como se pode notar, quando vivenciamos a invenção de novas técnicas, encontramo-nos em um processo complexo de mudança na cultura e na sociedade e, por isso, muitas vezes um temor se instala com relação às consequências que essas transformações podem trazer. Esse sentimento, no entanto, é frequentemente acompanhado por um fascínio por essas novas possibilidades de comunicação. Registros dessa sensação ambígua que ao mesmo tempo teme e anseia por mudanças são vistos não somente nos textos teóricos sobre o assunto, mas também em trabalhos de ficção. A literatura é repleta de exemplos, que já apareciam no início do século XIX, quando E.T.A. Hoffmann levantou essa questão no conto $O$ homem da areia. Na história, o fascínio de um homem por um autômato foi tamanho que ele se apaixonou, não se dando conta de que não se tratava de uma mulher real. Esse sentimento o levou à sua destruição e isso teria feito com que, a partir dali, aqueles que souberam do caso 
passassem a desconfiar de suas namoradas e namorados e a temer a possibilidade de também se apaixonarem por autômatos.

O medo e a ansiedade pelas possíveis consequências do advento de novas tecnologias são intensos principalmente porque elas têm a capacidade de desestabilizar um modo de organização cultural e social já instaurado. Uma pergunta frequente quando se está em um processo de adaptação a uma nova tecnologia é o que acontecerá com as mais antigas, consideradas muitas vezes obsoletas. Elas poderão coexistir com as recém inventadas ou haverá a destruição de alguma ou algumas? As técnicas que já existem poderão se adaptar às novas demandas da cultura ou perderão sua utilidade? Hoje, encontramo-nos fazendo essas perguntas e questionando as possibilidades da escrita nas plataformas impressas e digitais.

$\mathrm{Na}$ literatura contemporânea, é possível perceber um cenário de diluição de fronteiras entre as diversas áreas da produção cultural e notar que a narrativa migra entre diferentes dispositivos. O texto literário não está necessariamente ligado à plataforma impressa e pode ser encontrado em outros formatos, seja em blogs, sites, redes sociais ou na televisão. Como explica Vera Figueiredo, a tendência de interseção entre campos da produção cultural não é recente e já era vista, por exemplo, na relação entre literatura e jornalismo estabelecida no século XIX, que abriu espaço para mudanças como a publicação dos romances em capítulos sob a forma de folhetins e o surgimento do conto policial e da crônica moderna (FIGUEIREDO, 2010, p.12).

Não se pode afirmar, portanto, que essa migração do texto é uma característica própria da contemporaneidade. O que se pode perceber é que, diante das novas possiblidades que os dispositivos midiáticos oferecem, outras formas de manifestação desse fenômeno são vistas e interferem na dinâmica do campo artístico. É mais fácil, assim, entender a mudança pela qual os paratextos editoriais passam. O elemento paratextual, antes mais concentrado no meio impresso, manifesta-se de formas variadas, acompanhando um fenômeno mais amplo e não recente de migração de narrativas entre plataformas. É preciso deixar claro, portanto, que esse deslocamento de conteúdo em direção a vários canais é uma característica que está presente também na contemporaneidade e que se reflete no campo cultural, incentivando, assim, as constantes mudanças no meio literário e no mercado editorial.

A iniciativa de produzir paratextos em outras plataformas além da impressa cabe ao escritor e também ao mercado, já que o modo como o campo artístico se configura hoje confere maior visibilidade ao autor e a suas obras, o que contribui para a quantidade de livros vendidos. É possível perceber, desse modo, um investimento em páginas online por parte de escritores e de grandes editoras. O computador, nesse cenário, como aponta Figueiredo, toma espaço como um meio de convergência de narrativas. Para ela, a diminuição da distância entre os campos da arte permite que eles estejam centralizados nessa mídia, que armazena e distribui a produção artística (FIGUEIREDO, 2010, p. 18). É preciso destacar também, como ressalta Jenkins, que, mesmo com o importante papel que o computador assume hoje, a tendência não é a destruição dos meios antigos, e, sim, interações cada vez mais complexas entre as plataformas (JENKINS, 2009, p. 33). 
Ao se pensar a literatura no âmbito digital, mais especificamente no computador, é possível fazer uma reflexão também sobre a relação entre o meio e a obra. Por exemplo: ao deslocar o texto da mídia impressa para outra, ele se modificaria completamente ou preservaria suas características estéticas, estando somente veiculado em outra plataforma? Existiria uma propriedade específica de cada meio à qual a obra acabaria por se moldar ou o que importa de fato é o trabalho feito pelo artista no texto ou na imagem, sem levar em conta as possíveis especificidades de cada veículo? Pensadores como Roger Chartier e Jacques Rancière expressam opiniões divergentes sobre o assunto e podem, portanto, contribuir para pensá-lo.

Para Chartier, a existência dos novos suportes do texto escrito, como tablets e computadores, não significa necessariamente que haverá uma destruição dos meios antigos, porém ela implicaria em uma redistribuição dos papéis no que chama de "economia da escrita", e também em uma nova relação física e intelectual das pessoas com os textos (CHARTIER, 2002, p. 117). Ele aponta para o estabelecimento de uma linguagem universal não verbal, baseada em símbolos e emoticons, e acredita também que a leitura na tela do computador dificulta a percepção da "obra como obra" (CHARTIER, 2002, p. 23). Isso é, ele discute, entre outras coisas, a fragmentação do texto nas plataformas digitais e prevê um possível desaparecimento de critérios que possibilitam a classificação ou hierarquização dos discursos. De acordo com o pensamento de Chartier, o texto literário, ao migrar para outros dispositivos, seria modificado e sofreria influências da plataforma em que se encontra presente.

Já Rancière não vê uma distinção rigorosa entre os meios e defende que a imagem, independentemente da plataforma em que se encontra, é composta da relação lógica e paradoxal entre as "operações da arte, os modos de circulação da imageria e o discurso crítico” (RANCIÈRE, 2012, p. 27). Logo, para o filósofo, o que define a arte é a relação entre o trabalho do artista, as imagens comuns, do cotidiano, e também o distanciamento crítico de quem produz. Segundo ele,

É esse entrelaçamento da arte e da não-arte, da arte, da mercadoria e do discurso, que o discurso midialógico contemporâneo busca apagar, compreendendo sob essa denominação, para além da disciplina declarada como tal, o conjunto de discursos que pretendem deduzir das propriedades dos aparelhos de produção e de transmissão as formas de identidade e de alteridade próprias das imagens. (RANCIÈRE, 2012, p. 27)

O trabalho feito com as imagens e o texto, como se pode perceber, para Rancière, seria o definidor para a classificação das obras como objetos artísticos, e o meio na qual elas se encontram não as influenciaria diretamente. Essas questões contribuem também para pensar a literatura que ultrapassa os limites do meio impresso e é produzida em outros suportes. É preciso levar em consideração que a discussão, hoje, envolve ainda mais elementos que a questão da narrativa literária que é adaptada ao cinema, quadrinhos, jogos e outros gêneros. O mesmo texto literário pode ser produzido em diferentes plataformas de forma independente, não tendo necessariamente uma "obra original", e continuar estimulando o diálogo e as relações entre os suportes, como é o caso das obras transmídia. Assim, quando se faz uma reflexão sobre a 
literatura que é produzida em várias plataformas, é possível também pensar se o meio influenciaria ou não a obra no contexto de elaboração e deslizamento do texto literário entre diferentes suportes.

Esse trânsito entre plataformas acontece hoje também com os paratextos, que, no entanto, não devem ser confundidos com a obra transmídia. Ela é veiculada em diferentes mídias e suas narrativas podem ser lidas de forma independente, já eles, para Genette, seriam aparatos que completam e protegem o livro e, portanto, têm ligação direta e intencional com uma obra considerada principal. O elemento paratextual, como foi visto, pode ser produzido exclusivamente para ser veiculado em mídias digitais, mesmo que ainda mantenha, muitas vezes, relação com a plataforma impressa. Com a presença constante dos paratextos em outros dispositivos, é possível, além da questão da propriedade dos meios, pensar as possíveis novas interações do leitor com a obra, frequentemente mediadas pelo escritor ou pelo mercado editorial, e também refletir sobre uma mudança nas funções exercidas pelo autor.

Não se pode afirmar que o fato de os paratextos serem produzidos na internet $\mathrm{e}$ na televisão, por exemplo, é exclusivamente uma estratégia do mercado para atrair a atenção do leitor. A atitude de produzir conteúdo para outras mídias parte também do próprio autor, e é, ao mesmo tempo, bem recebida pelos leitores, que, desse modo, têm um acesso mais fácil e extenso à vida do escritor e aos bastidores da obra. $\mathrm{O}$ que se pode perceber é que o mercado editorial, assim como o campo artístico em geral, passa por transformações e que esses paratextos têm papel importante para sua estruturação e contribuem para alcançar um maior número de leitores, o que acaba por conferir maior popularidade ao autor, que se torna uma figura midiática.

Estando presente em diferentes plataformas e constantemente expondo suas opiniões, gostos e rotina em sites, blogs e redes sociais, o autor se torna uma figura de maior destaque e tem um discurso muitas vezes voltado para si. Pode-se perceber, na literatura contemporânea, um grande número de textos e paratextos voltados para a vida pessoal do autor, fato que não acontece devido ao caráter multimídia da literatura, mas é impulsionado e ganha mais espaço por causa dele. Ao refletir sobre esse fenômeno, Rancière (2003) explica que, na contemporaneidade, a ideia de propriedade da obra pelo autor passa por mudanças. $\mathrm{O}$ artista, hoje, devido principalmente ao caráter imaterial da produção, seria proprietário mais da ideia da obra do que de sua imagem. Ele se tornaria, então, um inventor, enquanto a imagem seria propriedade das editoras, produtoras e outras empresas. Para o filósofo francês, o fato de o gênero autobiográfico conceder ao autor também os direitos de imagem é um dos motivos pelos quais ele ganha tamanha popularidade e é explorado pelos escritores, seja nos livros ou nos paratextos.

Ainda que haja diversos outros motivos para a centralidade que a figura do autor vem ganhando e para o aumento de popularidade das escritas autobiográficas, não se tem como objetivo discuti-los aqui. O que se pretende é analisar essa nova dinâmica dos paratextos no campo literário, que, entre outras coisas, ajuda a conferir papel de destaque para o escritor. $\mathrm{O}$ autor, incentivado ou não pelo mercado editorial, exerce cada vez mais funções e passa a fazer, em paratextos, a mediação entre leitor e obra. 
Além de promover o próprio trabalho, ele também opina sobre outras produções, como livros e filmes, e acaba exercendo um papel que antes cabia preferencialmente aos críticos. Na literatura contemporânea, não são só os campos da produção cultural que vem se fundindo, mas também as funções do autor, do crítico e do editor estão cada vez menos claras e bem definidas. As fronteiras entre a esfera da produção e a da criação artística também se misturam, e o autor se vê ainda mais imerso no mercado de editoração, participando também de projetos, colunas, trailers e outros vídeos institucionais. Nesse cenário, o leitor se desloca entre textos e paratextos online e offline e acompanha produtos feitos para o computador e a televisão, que muitas vezes despertam seu interesse para a obra impressa.

$\mathrm{Na}$ literatura brasileira, o fenômeno dos paratextos também ganha força e se expande cada vez mais. É grande o número de blogs e sites institucionais, além de perfis de autores e editoras em redes sociais. Essa tendência de levar o leitor a migrar entre textos disponíveis na internet e que tem como objetivo a divulgação de livros já podia ser percebida, em 2007, com o Projeto Amores Expressos. Como parte dele, autores brasileiros ficaram um mês em alguma cidade fora do Brasil para escreverem romances ambientados nos lugares para onde foram. Mesmo que a meta do projeto fosse a produção de livros pelos escritores, ele não ficou restrito à plataforma impressa e se expandiu para a televisão, na qual ganhou formato de série, e para a internet. Cada autor, durante a viagem, atualizou um blog com a intenção de fazer dele uma espécie de diário com as experiências vividas fora do Brasil. Eles mantiveram os leitores informados sobre as impressões que tiveram das cidades e alguns relataram etapas do processo de escrita dos livros. A repercussão do projeto no ano em que foi lançado já evidenciava que a interação do leitor com a obra por meio da internet poderia ser um fenômeno bem-sucedido no mercado editorial brasileiro.

Outros paratextos que ganham espaço na cultura da convergência, estes declaradamente comerciais, são os trailers de livros. No blog da Companhia das Letras (Blog da Companhia), é possível ver uma grande quantidade de vídeos que promovem obras impressas, como é o caso de Todos nós adorávamos caubóis, de Carol Bensimon, cujo trailer tem mais de cinco mil visualizações no Youtube. O vídeo mostra flashes de um avião, um carro, uma estrada, hotéis e outros elementos presentes na obra, que é definida como uma road novel, e exibe também trechos do livro escritos e narrados em off. A mesma autora participa de outro vídeo, postado pela Companhia das Letras no canal da editora no Youtube, que tem por volta de quatro mil visualizações. Nele, Carol Bensimon conta a história de mais um romance de sua autoria, Sinuca embaixo d'água, em um cenário composto por mesas de sinuca, fazendo referência ao título do livro, e relata como surgiu a ideia da obra, da criação dos personagens, além de ler trechos do romance.

Nesse caso, percebe-se a presença forte da imagem em diálogo com a literatura. Ela acompanha o texto e estabelece diferentes relações com ele, tornando possível a existência de outras maneiras de fruição do leitor. Se refletirmos sobre o trailer de Todos nós adorávamos caubóis, por exemplo, e sua relação com o livro impresso, será possível notar uma mudança no formato dos paratextos e na maneira com que eles se 
apresentam e dialogam com a obra considerada principal. O livro de Bensimon narra a história de duas jovens que se reencontram e partem em uma viagem. Na orelha do livro, lê-se que

Cora e Julia não se falam há alguns anos. A intensa relação dos tempos da faculdade acabou de maneira estranha, com a partida repentina de Julia para Montreal. Cora, pouco depois, matricula-se em um curso de moda em Paris. Em uma noite de inverno do hemisfério norte, as duas retomam contato e decidem se reencontrar em sua terra natal, o extremo sul do Brasil, para enfim realizarem uma viagem de carro há muito planejada.

A orelha do livro impresso, também um paratexto, portanto, costuma resumir para o leitor que circula pelas livrarias e bibliotecas o que pode ser encontrado na obra com o objetivo de atrai-lo para ela. $\mathrm{O}$ trailer do livro também cumpre muitas vezes a função de chamar a atenção do leitor por meio de um resumo do livro, porém o faz a partir da representação da obra por imagens. Levando isso em conta, pode-se dizer que ambos, apesar de veiculados em plataformas diferentes, podem ser criados com o objetivo de despertar o interesse do leitor pelo o conteúdo do livro. No entanto, enquanto a orelha do livro não se separa fisicamente dele, o trailer só pode ser fruído nas plataformas digitais.

Assim, nota-se que o número de visualizações do vídeo pode ser completamente independente da quantidade de pessoas que de fato leram ou lerão o livro. Há trailers que se tornam virais na internet e chegam a pessoas que não têm necessariamente interesse de ter contato com a obra para além daquele vídeo e que, por estarem conectadas às plataformas em que o trailer circula, o tomam como uma obra separada, podendo desenvolver ou não posteriormente um interesse maior pelo conteúdo do livro. O trailer, portanto, exerce, muitas vezes, a mesma função de orelha ou contracapa de um livro, mas, como se encontra veiculado em outra plataforma e apresenta um conteúdo audiovisual, pode ser lido como uma obra independente, não tendo como objetivo apenas auxiliar a leitura de uma obra principal.

Ainda no Blog da Companhia, autores publicam artigos, entrevistas, diários e outros paratextos. Alguns escritores, como Carol Bensimon, Paulo Scott, Michel Laub e Luisa Geisler, têm colunas no site e, nelas, escrevem sobre assuntos diversos. Geisler, em 26 de maio de 2015, publicou uma coluna com o título "As 15 coisas que sei sobre meu próximo livro", e listou alguns elementos do romance que ela ainda estava escrevendo, como o nome da protagonista e uma previsão de quantas partes ou páginas ele terá. Isso mostra, assim como os blogs relacionados ao Projeto Amores Expressos e também os trailers de livros, que os paratextos podem chamar a atenção também para uma obra que ainda não foi publicada, isso é, eles muitas vezes existem antes da obra considerada principal. Além do Blog da Companhia, outro exemplo de site que publica paratextos é o blog do Instituto Moreira Salles (Blog do IMS). Nele, autores também postam textos variados e até conversam entre si, como foi o caso da seção de correspondência, em 2012, em que trocavam cartas relatando experiências pessoais. 
Já o Facebok, o Twitter e o Instagram são exemplos de redes sociais em que paratextos editoriais são publicados. Em agosto de 2014, a Editora Rocco lançou um projeto em que convida periodicamente um escritor para ser, durante uma semana, o responsável pela conta da editora no Instagram. Cada autor escolhido tem a função de postar fotos e pequenos textos sobre a sua rotina com a hashtag "vida de escritor" (\#vidadeescritor). O projeto permite que os leitores conheçam melhor os escritores e compartilhem dados sobre eles, o que funciona como uma possível maneira de chamar a atenção para suas obras e também de fazer com que os leitores que seguem a editora na rede social conheçam mais escritores de seu catálogo.

Como parte desse projeto, a autora de livros adolescentes Thalita Rebouças comandou a conta da Rocco no Instagram na segunda semana de março de 2015. Ela postou fotos de um lançamento de livro, de presentes de fãs e chegou a publicar um vídeo que mostra ela malhando em uma academia. O escritor Marcelo Moutinho, em maio do mesmo ano, postou fotos relacionadas à mudança de casa que fazia na época, a maioria delas com mais de mil "curtidas", compartilhando com o leitor as caixas que guardavam seus pertences e a vista do novo local onde moraria.

Assim, fica evidente que, com esses paratextos publicados na internet, a figura do autor ganha mais espaço no campo literário, não somente por causa das obras que escrevem, mas sua vida pessoal também é tema de projetos e chama a atenção do leitor. Ao seguir a rede social de uma editora, o leitor recebe uma grande quantidade de informações sobre os autores e acaba muitas vezes desenvolvendo um interesse pela vida pessoal do escritor. Em consequência disso, ele pode também querer conhecer e ter acesso às obras dos escritores que mais lhe interessarem. Como diz Philippe Lejeune (2008), se antes conhecíamos a obra e imaginávamos o autor, hoje a tendência é conhecermos o autor para imaginarmos a obra, que muitas vezes não leremos.

Com os paratextos, portanto, a presença multimídia do texto faz com que a figura do autor seja exibida de forma recorrente não apenas no livro impresso, mas também em outras plataformas. Tanto na obra impressa, com o aumento de popularidade das narrativas autobiográficas e autoficcionais, quanto na divulgação feita nas redes sociais e na televisão, a imagem e os pensamentos dos autores aparecem como um meio de atrair o público, o que gera um interesse ainda maior pela sua figura. Ao analisar a presença do autor em mídias como rádio e televisão, Lejeune questiona:

Será que, ao tornarem o autor contemporâneo acessível a todos, o rádio e a televisão exercem uma função salutar, dissipando o efeito de mistério engendrado pela escrita? Só na aparência. Pois, na realidade, a mídia incentiva fatalmente a ilusão biográfica que leva a buscar a solução do mistério no próprio autor. (LEJEUNE, 2008, p.195)

Ainda segundo ele,

Na televisão, enfim, voz e imagem se reuniram. Nada mais a ser imaginado: o autor do livro que lemos ou, com mais frequência, do livro que não lemos e que não leremos está ali, em carne e osso e ao vivo. Se ainda restar algo a ser imaginado, será, paradoxalmente, o que ele terá escrito. (LEJEUNE, 2008, p.194) 
Desse modo, é possível perceber que a migração de alguns leitores entre plataformas é feita, muitas vezes, devido ao esforço do mercado editorial para fazê-lo acompanhar o trabalho e as opiniões de um escritor específico. No entanto, mesmo que a participação e o investimento do mercado nesses paratextos sejam grandes, não é correto afirmar que esse aumento do número de paratextos na internet e na televisão se deve somente por causa dele, e nem que o único intuito desse investimento é aumentar o número de vendas. Os paratextos, como aponta Genette, têm função importante para orientar a leitura da obra e exercem papel fundamental para a organização e para a própria existência de um texto como livro.

Além da questão do aumento de popularidade da figura do autor nas plataformas digitais, ao se pensar sobre a presença massiva do texto literário em redes sociais como o Instagram, em que as imagens predominam sobre o texto, nota-se que a escrita vem deixando de ser hegemônica no meio literário. Figueiredo, no texto Mercado de bens simbólicos e interseção dos campos artísticos na cultura multimídia, aponta para uma nova lógica do campo literário no contexto hipermidiático. Ela ressalta que

$\mathrm{Na}$ era da tecnologia digital, filmes, fotografias, textos, músicas, traduzidos em dados numéricos, inserem-se numa rede não hierárquica de circulação. Torna-se importante lembrar, então, que, face a essa contínua torrente de transformação intertextual, num processo incessante de reciclagem, textos literários vêm cada vez mais assumindo o lugar de intermídia, para usar a expressão de Youngblood, servindo de prototexto no campo da produção cinematográfica, televisiva e digital. (FIGUEIREDO, 2015, p. 6)

Desse modo, torna-se mais fácil refletir sobre a multiplicação dos paratextos na internet, onde ganham outros formatos e estabelecem diferentes ligações entre si, e, assim, pensar também sobre algumas mudanças no campo da literatura. Ainda que não seja o objetivo do artigo se aprofundar no conceito de literatura expandida, é importante ter consciência de que, na cultura digital, vídeos, fotografias e áudios, por exemplo, também cumprem o papel de unir e estabelecer um diálogo com textos, fazendo parte do campo literário e formando, antes de tudo e paradoxalmente, uma cultura predominantemente visual em meio a um número cada vez maior de textos que, devido ao modo como estão dispostos na tela, acabam por criar também um apelo visual diante dela.

No artigo Entre o texto e a imagem: a literatura equilibrista, Figueiredo aponta ainda para mudanças na relação entre texto e imagem quando se trata do entrelaçamento entre os campos da literatura e do cinema, e sinaliza uma perda da supremacia do primeiro, que funcionaria, cada vez mais, como "repositório de histórias a serem retrabalhadas para exibição nas telas" (FIGUEIREDO, 2012, p. 142). Hoje, portanto, estaríamos vivendo uma perda de hegemonia da cultura impressa e as imagens seriam utilizadas de forma cada vez mais recorrente, junto com os textos, na literatura. Essa mudança seria incentivada pela aceleração do processo de deslizamento do texto entre plataformas, promovendo uma descentralização dos campos e discursos. Para Chartier, o computador rompe com uma oposição que antes estabelecia que as telas seriam os suportes das imagens e os livros, dos textos. Segundo Chartier, hoje, essa oposição "é 
substituída por uma nova situação que propõe um novo suporte para a cultura escrita e uma nova forma para o livro" (CHARTIER, 2002, p. 106).

Como se pode perceber, as transformações que acompanham o advento de novas tecnologias acontecem também no meio da arte. Torna-se cada vez mais difícil refletir sobre arte hoje sem levar em consideração essa mudança de cenário que envolve diferentes modos de comunicação e de produção de textos. Para Steven Johnson, não faz nem nunca fez sentido pensar o mundo da tecnologia e o da arte de forma separada. Segundo ele, temos o hábito de imaginá-los dessa forma, como dois "afluentes correndo incessantemente para o mar da modernidade e dividindo, em seu curso, o mundo em dois campos: os que habitam nas margens da tecnologia e os que habitam nas margens da cultura" (JOHNSON, 2001, p.7). Johnson defende que hoje começa-se a afirmar mais frequentemente que esses dois mundos se misturam porque, com a velocidade das transformações na tecnologia, essa conexão fica evidente. No entanto, para ele, a fusão fez parte de nossa experiência desde o primeiro pintor de cavernas.

O teórico, em Cultura da interface, pensa os elementos do design de interface como elementos artísticos e afirma que nosso fascínio pelos computadores gráficos vem do fato de eles não se amarrarem à representação do mundo dos objetos tal como o conhecemos. Apesar de poderem imitar esse sistema, tem-se a possibilidade de "adotar novas identidades e desempenhar novas tarefas que não têm absolutamente nenhum equivalente no mundo real" (JOHNSON, 2001, p.49). Ainda segundo ele, o uso de uma nova tecnologia pode alterar nosso modo de escrever. Quando utilizamos o processador de textos, para Johnson, conceberíamos nossas frases de maneira diferente, não só por causa das ferramentas disponíveis, mas também porque o computador transformaria o processo de pensamento que se desenrola durante o ato da escrita (JOHNSON, 2001, p.105). Essa outra relação com os textos teria dado início a um estilo de escrita diferente, mais descontraído e coloquial, que estaria hoje sendo incorporado em nossa comunicação.

A constatação dessas mudanças no campo da comunicação remete novamente à transição entre uma cultura impressa e outra digital e nos levam, finalmente, à possibilidade de esboçar pensamentos mais contundentes sobre as transformações no campo da arte. Pode-se questionar até que ponto os elementos que regiam a arte produzida na cultura impressa ainda são pertinentes se aplicados à nova cultura que vem se formando e, assim, pensar o lugar dos paratextos que migram do livro para o computador. Eles se encontram presentes em um ambiente ainda pouco explorado e que, no entanto, já indica outra lógica de interação entre textos, autores e leitores, que se relacionam de forma menos hierarquizada e não se encontram necessariamente restritos a divisões entre áreas do saber. Aqui, apropriados ou não pelo mercado editorial, texto, imagem e som dialogam entre si e confundem ainda mais as já borradas fronteiras entre as áreas do saber.

Outro exemplo desse diálogo pode ser visto com a publicação do folhetim no formato de e-book Delegado Tobias, de Ricardo Lísias, pela editora e-galáxia. Na história, o delegado é encarregado de investigar a morte de Lísias, que teria sido assassinado. Para explorar o assunto fora do livro, o escritor criou, no Facebook, um 
perfil com o nome Delegado Tobias e adicionou leitores que o seguiam na rede social. O fake, que fez mais de trezentos "amigos", passou a atuar como Tobias e a se comunicar com a página do próprio autor, criando tramas fora do texto considerado principal.

O perfil do personagem, nesse caso, ultrapassou o diálogo com a história e ganhou personalidade e independência ao compartilhar matérias sobre assuntos cotidianos, como futebol. O leitor, então, passou a acompanhar diariamente a trama do personagem, que podia ou não estar relacionada com a história presente no livro digital. $\mathrm{O}$ escritor simulou em seu perfil oficial trocas de cartas e de e-mails com o personagem de Tobias e chegou a falar que estava sendo processado pelo personagem, que o acusava de "fazer autoficção com o seu nome". Isso mostra que, no caso da obra Delegado Tobias, o paratexto do livro contribui, inclusive, para a construção do próprio personagem Tobias, acrescentando mais possibilidades de leitura para a obra e dialogando diretamente com o texto considerado principal. O leitor, então, na obra de Lísias, acompanhou em tempo real os paratextos que excediam os limites do texto do livro, presenciando seus desdobramentos e podendo, assim, "curtir", compartilhar e acrescentar saberes ao que era produzido.

Nota-se, portanto, uma mudança de paradigma no campo cultural, mais evidente devido às transformações tecnológicas, que potencializam esse fenômeno e afetam a relação entre leitor, autor e obra, que fica cada vez mais direta. $\mathrm{O}$ autor faz papel também de crítico e de editor, dando dicas para leitores e ajudando os editores na elaboração de projetos. $\mathrm{Na}$ contemporaneidade, é comum a interseção das fronteiras entre áreas do meio artístico e, além disso, a divisão de papéis no campo literário também está cada vez menos nítida e bem definida. A mediação entre obra e público cabe cada vez mais ao escritor e, nesse cenário, os paratextos ganham papel de destaque.

Como as visualizações e os compartilhamentos tornam esses paratextos virais e possibilitam um grande acesso por parte do público, aumentando o sentimento de participação do leitor na obra, é possível, por fim, refletir sobre a crescente importância que eles assumem em comparação à obra considerada principal. É comum o paratexto, na esfera da internet, atingir mais pessoas do que o texto considerado principal da obra. É importante, então, repensar o conceito apontado por Genette, que os coloca apenas como aparatos que completam e protegem o livro e, assim, perceber que, hoje, com o maior trânsito do leitor entre plataformas, eles exercem também outras funções e ganham mais destaque no campo literário, seja influenciando o modo de leitura da obra, contribuindo ainda mais para o número de vendas ou conferindo maior popularidade ao autor midiático.

\section{Referências}

BENSIMON, Carol. Todos nós adorávamos caubóis. São Paulo: Companhia das letras, 2013.

CHARTIER, Roger. Os desafios da escrita. São Paulo: Editora UNESP, 2002. 
FIGUEIREDO, Vera Lúcia Follain de. Entre o texto e a imagem: a literatura equilibrista. In: OLINTO, Heidrun Krieger; SCHØLLHAMMER, Karl Erik (orgs.).

Literatura e criatividade. Rio de Janeiro: 7Letras, 2012. p. 141-154.

FIGUEIREDO, Vera Lúcia Follain de. Mercado de bens simbólicos e interseção dos campos artísticos na cultura multimídia. In: Compós, 24., 2015. Brasília, 14 p.

FIGUEIREDO, Vera Lúcia Follain de. Narrativas migrantes: literatura, roteiro e cinema. Rio de Janeiro: 7Letras, 2010.

FLUSSER, Vilém. A escrita - há futuro para a escrita? São Paulo: Annablume, 2010 .

GENETTE, Gérard. Paratextos editoriais. São Paulo: Ateliê Editorial, 2009.

HOFFMANN, E.T.A. O homem da areia. In: Contos fantásticos. Rio de Janeiro: Imago, 1993.

JENKINS, Henry. Cultura da convergência. São Paulo: Aleph, 2009.

JOHNSON, Steven. Cultura da interface: como o computador transforma nossa maneira de criar e comunicar. Rio de Janeiro: Zahar, 2001.

LEJEUNE, Phillippe. O pacto autobiográfico: de Rousseau à internet. Belo Horizonte: UFMG, 2008.

LÉVY, Pierre. Cibercultura. São Paulo: Editora 34, 2010.

RANCIÈRE, Jacques. Autor morto ou artista vivo demais?. Folha de São Paulo, São Paulo, 6 abr. 2003.

RANCIÈRE, Jacques. O destino das imagens. Rio de Janeiro: Contraponto, 2012. 